\title{
PENDIDIKAN MULTIKULTURAL DALAM PEMBELAJARAN SEJARAH LOKAL
}

Supardi

Fakultas Ilmu Sosial Universitas Negeri Yogyakarta

\begin{abstract}
Abstrak
Pendidikan multikultural merupakan konsep pendidikan yang mengakui perbeda-an/keberagaman dalam suatu bingkai kebersamaan dan kesederajatan. Konsep pendidikan multikultural relevan dalam konsep negara yang mempunyai keanekaragaman budaya seperti Indonesia. Pendidikan merupakan salah satu media efektif untuk mengembangkan kesadaran multikulturalis. Pendidikan sejarah, merupakan salah satu konsep pendidikan yang bertujuan untuk membangun sikap demokrasi dan nasionalisme dan kesadaran multikultural. Salah satu unit sejarah yang mengkaji heterogenitas bangsa Indonesia adalah sejarah lokal. Tulisan ini bertujuan untuk mengetahui 1) peranan pendidikan sejarah lokal dalam mengembangkan kesadaran multikultural; dan 2) konsep pengajaran sejarah lokal yang efektif untuk mengembangkan kesadaran multikultural. Kajian sejarah lokal mampu memberikan kesadaran sejarah keberagaman masyarakat padaa siswa. Melalui kajian perbedaan masa lalu setiap masyarakat, kesadaran multikultural dapat terbentuk. Pengajaran sejarah lokal dapat dilakukan melalui tiga model: 1) mempelajari tentang pengalaman masa lalu; 2) studi kasus berbagai perbedaan; 3) pengembangan strategi pembelajaran; 4) pengembangan kurikulum; dan 5)menyisipkan pengajaran sejarah lokal dalam materi yang berhubungan dengan sejarah nasional.
\end{abstract}

Kata kunci: sejarah lokal, pendidikan

\section{MULTICULTURAL EDUCATION IN LOCAL HISTORY LEARNING}

\author{
Supardi \\ Fakultas Ilmu Sosial Universitas Negeri Yogyakarta
}

\begin{abstract}
Multicultural education is an educational concept which admits cultural differences in the egality and equality. This concept is still relevant to the nation concept that has cultural differences as Indonesian. Education, is one of the effective media for multiculturalism development. History education has concepts which aim to build democracy, nationalism, and multiculturalism character. One of the historical units which studies Indonesians heterogenity is local history. This article aims to identify; 1) the role of local history education to building multicultural awareness; and 2) the concept of effective local history education to develop multicultural education. Local history studies can give the historical awareness of society's diversity to students. Through the studies of social differences in the past, multicultural awareness will develop. Local history teaching can be done in five models; 1) learning about the past; 2) studying case of social differences; 3) developing instructional strategies; 4) developing the curricula; 5) integrating local history in the subjects relevant to national history.
\end{abstract}

Keywords: multicultural, local history, education 


\section{PENDAHULUAN}

Indonesia adalah negara multikultural, ditunjukkan oleh deferensiasi sosial dalam bentuk perbedaan etnis, sosial, budaya, agama, dan sebagainya. Menurut data Leo Suryadinata (Tilaar, 2004, p.113) setidaknya terdapat 20 suku bangsa besar di Indonesia. Berdasarkan data tahun 2001, etnis Jawa adalah etnis terbesar jumlahnya 83,9 juta $(41,7 \%)$, kemudian disusul etnis Sunda 31 juta $(15,4 \%)$, etnis Melayu, Madura, Batak, Minangkabau, Betawi, Bugis dan Banten yang masingmasing jumlahnya sekitar 4-7 juta atau 2\%4.5\%. Masyarakat Tionghoa merupakan etnis dengan jumlah warganya sebanyak 1.738 .936 jiwa $(0,86 \%)$.

Negara multikultural seperti Indonesia harus antisipatif dan responsif terhadap fenomena heterogenitas dengan arif dan bijak. Dalam satu sisi, perbedaan telah menimbulkan sisi negatif berupa konflik yang melanda negeri ini seperti yang terjadi dalam kasus konflik antarsuku di Sambas Kalimantan Tengah, konflik dengan isu agama di Poso dan Malu$\mathrm{ku}$, gerakan separatisme Aceh. Indonesia harus mengakui adanya perbedaan yang ada dalam masyarakat negeri ini, bukan sekedar perbedaan deskriptif tetapi perbedaan normatif. Maksudnya adalah bahwa perbedaan yang ada bukan sekedar 'diketahui', tetapi harus 'disadari' dalam kehidupan yang egaliter dan demokratis. Tanpa upaya kesadaran multikultural, niscaya nasionalisme yang selama ini dibangun, akan tercabik-cabik oleh konflik dan gerakan separatisme. Untuk mengembangkan kesadaran multikultural itulah perlu dilakukan pendidikan multikultural (Multicultural Education).

Salah satu media efektif pendidikan multikultural adalah melalui pendidikan sejarah lokal. Mengapa sejarah lokal dapat menjadi media penting dalam pendidikan multikultural? Apakah justru tidak akan menyebabkan sikap tribalisme? Bagaimana cara strategi pendidikan multikultural dalam pembelajaran sejarah lokal?

\section{Pendidikan Multikultural}

Salah satu perangkat efektif untuk mewujudkan kesadaran dan kesedererajatan dalam keberagaman adalah konsep pendidikan multikultural. Pendidikan multikultural menurut Nietto (2002, p.300) adalah:
“... a process of comprehenshive school reform and basic education for all student. It chalenges ang rejects racism and other forms of discrimination in school and society and accepts and affirms the pluralism (ethnic, racial, linguistic, religious, economic, and gender among others) that students, their communities, and teacehr represent. "

Terdapat 7 karakteristik dasar pendidikan multikultural yakni pendidikan multikultural sebagai; pendidikan anti rasisme, pendidikan dasar, penting untuk semua siswa, pervasive, pendidikan untuk perdamaian, sebuah proses, dan critical pedagogy. (Nieto, 2002, p.300)

Frazier dan Garcia seperti yang dikutip Tilaar (2004, p.122), menyatakan bahwa yang dimaksud dengan pendidikan multikultural adalah:

"Multicultural education is a concept, a frame work, a way of thingking, a philosophical view point, a value orientation, and a set of criteria for making decision that better serve the educational needs of culturally diverse student populations"

Sedangkan menurut Musa Asyarie, (2004) yang dimaksud dengan pendidikan multikultural adalah proses penanaman cara hidup menghormati, tulus, dan toleran terhadap keanekaragaman budaya yang hidup di tengah-tengah masyarakat plural. Dengan pendidikan multikultural, diharapkan adanya kekenyalan dan kelenturan mental bangsa menghadapi benturan konflik sosial, sehingga persatuan bangsa tidak mudah patah dan retak. Dari berbagai pendapat di atas dapat disimpulkan bahwa pendidikan multikultural merupakan ide, cita-cita, kesamaan pandangan, dan strategi menanamkan kesadaran multikultural melalui pendidikan.

Kunci penting tujuan pendidikan multikultural menurut Banks adalah "... to helps individuals gain greater self-understanding by viewing themselves from the perspective of othe cultures" (2002, p.1). Pendidikan multikultural berasumsi bahwa dengan saling mengerti dan memahami maka akan diikuti oleh sikap saling respek.

Bagaimana cara melakukan pendidikan multikultural? Banks \& Banks seperti yang dikutip Tilaar, (2004, p.182) berpendapat bah- 
wa terdapat lima tipologi pendidikan multikultural yang berkembang, yakni:

1. Mengajar mengenai kelompok siswa yang memiliki budaya yang lain (cultural difference)

2. Hubungan manusia (human relation), membantu siswa dalam melakukan percampuran antarkelompok

3. Single group studies, yakni program yang mengajarkan hal-hal yang memajukan pluralisme tetapi tidak menekankan adanya stratifikasi sosial dalam masyarakat

4. Pendidikan multikultural, reformasi pendidikan yang menyediakan kuriukulum serta materi pelajaran yang menekankan kepada adanya perbedaan siswa dalam bahasa, yang keseluruhannya untuk memajukan pluralisme kebudayaan dan ekualitas sosial.

5. Pendidikan multikultural yang sifatnya rekonstruksi sosial, dengan tujuan menyatukan keberagaman dan menantang ketimpangan sosial yang ada dalam masyarakat.

Bagaimana membangun konsep pendidikan multikultural untuk Indonesia? Terdapat enam konsep yang ditawarkan Tilaar untuk membangun konsep pendidikan multikultural di Indonesia (2004, pp.185-191).

1. "Right to culture" dan identitas budaya lokal, sebagai manifestasi jawaban globalisasi. Hal ini dimaksudkan untuk menjaga dan menunjukan identitas kebudayaan.

2. Kebudayaan Indonesia yang menjadi, yakni mewujudkan sistem nilai ke-indonesiaan di tengah sistem keberagaman.

3. Konsep pendidikan multikultural normatif, bukan sekedar deskriptif. Pendidikan multikultural normatif tidak hanya mendeskripsikan adanya pluralitas, melainkan misi untuk mewujudkan kebudayaan Indonesia yang dimiliki oleh suatu negara-bangsa.

4. Pendidikan multikultural merupakan suatu rekonstruksi sosial, yakni sebagai alat untuk melihat kembali kehidupan sosial yang ada dewasa ini.

5. Pendidikan multikultural di Indonesia memerlukan pedagogik baru, yang tidak hanya terbatas dalam pendidikan sekolah. Pedagogik baru telah mengembangkan pemberdayaan dan kesetaraan sesama manusia dengan keberagaman budaya.

6. Pendidikan multikultural bertujuan untuk mewujudkan visi Indonesia masa depan serta etika berbangsa.

Untuk mendukung terlaksananya enam konsep pendidikan multikultural, idealnya dilakukan beberapa program prioritas pendidikan multikultural. Beberapa pengembangan yang bisa dilakukan adalah, menjadikan lembaga-lembaga pendidikan sebagai pusat budaya, menyusun kurikulum kewarganegaraan, penyusunan kurikulum pendidikan multikultural, kebijakan perbukuan, dan pendidikan guru.

Dalam sistem pendidikan, pendidikan multikultural melibatkan seluruh bagian sistem pendidikan dan stakeholder yang ada. Masing-masing mata pelajaran tidak bisa dipandang secara parsial, melainkan mempunyai hubungan yang sifatnya interdisiplin, atau justru integral. Masing-masing bidang studi mempunyai misi dan tugas untuk mengembangkan pendidikan multikultural sesuai dengan relevansinya.

Terdapat lima dimensi penting dalam pendidikan multikultural menurut Banks (2002, p.13) yakni integrasi isi, proses konstruksi pengetahuan, reduksi prasangka buruk (prejudice), kesamaan pendidikan, dan pemberdayaan budaya dan struktur sekolah. Pendidikan multikultural harus mampu melaksanakan pengembangan bahan ajar yang luas membangun berbagai contoh yang dapat dipelajari peserta didik.

\section{Pendidikan Sejarah dan Sejarah Lokal}

Berdasarkan uraian tentang konsep pendidikan multikultural yang ditawarkan Tilaar di atas, maka sangat jelas bahwa sejarah berperan penting dalam pendidikan multikultural. Pendidikan sejarah berperan penting dalam internalisasi dan pembangunan kesadaran sejarah. Pendidikan sejarah mampu mampu menjadikan berbagai perbedaan sejarah masa lampau sebagai suatu pelajaran untuk masa depan lebih baik. Dalam kenyataannya sudahkah pembelajaran sejarah dalam sistem pendidikan selama ini telah mengembangkan pendidikan multikultural secara efektif? Sudahkah pengajaran sejarah memunculkan berbagai fakta keberagaman masa lalu hingga 
masa kini, yang mampu menum-buhkan kesadaran siswa akan keberagaman tersebut?

Tujuan pengajaran sejarah di sekolah mengacu pada tujuan pendidikan nasional yang tercantum dalam pasal 3 UU RI No 20 Th. 2003 tentang SISDIKNAS, bahwa tujuan pendidikan nasional adalah "... untuk berkembangnya potensi peserta didik agar menjadi manusia yang beriman dan bertakwa kepada Tuhan Yang Maha Esa, berakhlak mulia, sehat berilmu, cakap, kreatif, mandiri dan menjadi warga negara yang demokratis serta bertanggungjawab."

Tujuan pengajaran bukan sekedar transfer of knowledge, tetapi juga transfer of value, bukan sekedar membelajarkan siswa menjadi cerdas, tetapi juga berakhlak mulia. Pengajaran sejarah selain bertujuan untuk mengembangkan keilmuan, juga mempunyai fungsi didaktis. Fungsi didaktis pengajaran sejarah telah dinyatakan secara implisit dan eksplisit, seperti yang dinyatakan Sartono Kartodirdjo (1992, p.252) "bahwa maksud pengajaran sejarah adalah agar generasi muda yang berikut dapat mengambil hikmah dan pelajaran dari pengalaman nenek moyangnya".

Secara lebih detail, Brian Garvey dan Mary Krug (1977, pp.2-5) mengidentifikasikan bahwa mempelajari sejarah mempunyai bebe-rapa maksud, yang diantaranya:

a) to acquire knowledge of historical facts

b) to gain an understanding or appreciation of past events or periods or people

c) to acquire the ability to evaluate and criticize historical writing

d) to learn the techniques of historical research

e) to learn how to write history

Pengajaran sejarah pada pendidikan SD dan SMP masih mengacu pada tujuan pertama dan kedua. Sedangkan untuk SMA telah menyentuh sebagian tujuan ketiga sampai kelima.

Baik ditinjau dari sistem pendidikan maupun implementasinya, pengajaran sejarah selama ini masih banyak dikeluhkan. Sebagian keluhan tersebut adalah kurikulum pendidikan sejarah yang terlalu sarat dengan materi, kurang merangsang siswa berfikir kritis, atau terlalu indoktrinatif. Pengajaran sejarah sering dijadikan alat legitimasi penguasa dengan penonjolan tokoh-tokoh pen- ting dalam Sejarah Nasional Indonesia. Kurikulum cenderung uniform, bahkan hingga materi dan soal yang diajarkan kepada siswa. Kurikulum belum bisa dikembangkan dengan menonjolkan kasus-kasus lokal yang lebih dekat dan menyentuh siswa. Akibatnya, siswa merasa jenuh, bahkan asing dengan pembelajaran yang mereka alami.

Dalam implementasi pembelajaran di kelas, guru belum berhasil mengembangkan suasana pembelajaran yang variatif. Mereka selalu mengedepankan sistem pembelajaran ekspositoris yang menonjolkan pengembangan domain kognitif Tidaklah mengherankan kalau kemudian banyak siswa apatis dan skeptis pada mata pelajaran sejarah. Pengajaran sejarah masih berorientasi pada penyajian fakta, belum berorientasi pada upaya penghayatan dan kesadaran sejarah, seperti keprihatinan Soegjatmoko yang dikutip I Gde Widja (1989, p.11) sebagai berikut:

“ Pengajaran sejarah hendaknya diselenggarakan sebagai suatu avontuur bersama dari pengajar maupun yang diajar. Dalam konsep ini maka bukan hafalan fakta, melainkan riset bersama antara guru dengan siswa/mahasiswa menjadi metode utama. Dengan jalan ini maka si mahasiswa langsung dihadapkan dengan tantangan intelektual yang memang merupakan ciri khas daripada sejarah sebagai ilmu... Dia menjadi peserta, pelaku dalam usaha "penemuan diri' bangsa kita sendiri"

Berkaitan dengan buku pelajaran yang digunakan dalam pembelajaran, masih didominasi oleh penerbit dan penulis dari Jawa. Tidak mengherankan kalau fakta-fakta yang ada dalam buku mata pelajaran tersebut kering dengan kasus-kasus di berbagai daerah. Bukan berarti bahwa penulis dan penerbit Jawa tidak memahami sejarah daerah lain, tetapi penulis yang lebih dekat dengan objek sejarah, setidaknya akan lebih empatif dan diversif dalam mengembangkan bahan ajar.

Pengajaran Sejarah Nasional Indonesia, dimaksud sebagai salah satu usaha penanaman kesadaran sejarah bangsa Indonesia pada siswa. Apa yang dikenal dengan Sejarah Nasional Indonesia, adalah sejarah bekas wilayah Hindia Belanda. Batasan sejarah nasional bersifat politis administratif sebagai 'sejarah bangsa Indonesia' yang eksistensi politisnya 
resmi sejak proklamasi 17 Agustus 1945. Sejarah Nasional Indonesia selanjutnya diturunkan dalam sejarah daerah yang meliputi sejarah berbagai daerah di Indonesia dengan batasan administratif propinsi atau kabupaten.

Di luar kedua batasan sejarah sejarah nasional dan daerah, muncul sejarah lokal, yang menurut Taufik Abdullah (1996) didefinisikan sebagai "sejarah dari suatu tempat", suatu locality, yang batasannya ditentukan oleh perjanjian penulis sejarah. Penulis mempunyai kebebasan menentukan batasan penulisannya, apakah dengan skope geografis, etnis, yang luas atau sempit. Sejarah lokal bersifat elastis, bisa berbicara mulai hanya mengenai suatu desa, kecamatan, kabupaten, tempat tinggal suatu etnis, suku bangsa, yang ada dalam satu daerah atau beberapa daerah.

Penulisan sejarah lokal mempunyai makna penting baik untuk kepentingan akademis maupun pembangunan masyarakat, terutama kepentingan masyarakat dalam mempelajari pengalaman masa lalu nenek moyangnya. Hal ini sejalan dengan yang diungkapkan Allan J Ligthman (1978, p.169)

\section{“... local history conducted for their own sake, local history conduct to test hypo- theses about broader jurisdictions, usu- ally nation states, and local history that focus on understanding the process by which communities grow and develop. Although analytically distinct, in actual practise these lines frequently crisscross and run together"}

Dalam batasan spasial/waktu dalam sejarah lokal, penulispun bisa membuat batasan terpendek hingga panjang. Penulisan tentang sebuah pemberontakan PETA, bisa dibuat dalam ritme pendek maupun panjang.

Dalam seminar Sejarah Lokal 17-20 September 1984 di Medan, telah dikemukakan lima tema pokok sebagai acuan penulisan sejarah lokal seperti yang dikutip Kuntowijoyo (2003, p.145): (1) dinamika masyarakat pedesaan; (2) pendidikan sebagai faktor dinamisasi dan interaksi sosial; (3) interaksi antarsuku bangsa dalam masyarakat majemuk; (4) revolusi nasional di tingkat lokal; (5) biografi tokoh lokal.

Dalam bagian lain, Taufik Abdullah (1992, p.239) menambahkan bahwa penulisan sejarah lokal begitu besar artinya dalam upaya pembahasan yang lebih detail tentang feno- mena dan peristiwa nasional yang bersifat fragmentaris. Sejarah lokal diharapkan mampu memberikan sumbangan berupa kesadaran sebagai bangsa yang multi budaya, ditunjukan dengan pengakuan akan kelemahan masingmasing dengan membangun kesederajatan di antara kebhinekaan.

Bagi kepentingan sejarah nasional, sejarah lokal tidaklah bersifat antagonis, justru akan memberi kontribusi positif, seperti yang disampaikan Taufik Abdullah (1990, p.243) sebagai berikut:

“... bahwa sejarah lokal dengan pendekatan yang tidak bersifat involusi, yang hanya berkisar pada dirinya, makin memberi kemungkinan untuk merintis permasalahan baru dalam sejarah nasional. Dengan begini bukan saja visi tentang proses ke arah terwujudnya kesadaran nasional, sebagai syarat utama bagi kemantapan integrasi nasional dapat dipersegar, tetapi dan lebih penting lagi, dinamika sesungguh-nya dari proses terjadi itu dapat dipahami",

Corak studi sejarah lokal yang telah dilakukan tentang Indonesia menurut Taufik Abdullah (1992, p.27) dapat dibedakan menjadi empat golongan, yakni: (1) studi yang difokuskan pada suatu peristiwa tertentu (studi peristiwa khusus atau apa yang disebut evenemental l'evenement; (2) studi yang lebih menekankan pada struktur; (3) studi yang mengambil perkembangan aspek tertentu dalam kurun waktu tertentu (tematis); dan (4) studi sejarah umum yang menguraikan perkembangan daerah tertentu (propinsi, kota, kabupaten) dari masa ke masa.

Sejarah lokal lebih bersifat demokratis, sebab ia berangkat dari fenomena setempat, berbeda dengan sejarah daerah yang dibatasi secara administratif politik. Namun, bisa saja sebuah sejarah daerah merupakan sejarah lokal, misalnya tentang Sejarah Bali. Bali adalah wilayah administratif yang mempunyai latar belakang sosial budaya yang relatif sama. Hal ini berbeda ketika kita berbicara tentang Sejarah Daerah Jawa Tengah. Harus diingat, bahwa Jawa Tengah bagian Barat merupakan masyarakat yang mempunyai latar belakang sosial budaya suku Sunda, yang secara kultur berbeda dengan masyarakat Jawa Tengah (Solo atau Semarang). Sejarah lokal mempunyai keleluasaan yang lebih 
independen dalam menentukan wilayah kajiannya. Kajian sejarah lokal yang intensif dan diversif, akan mampu memunculkan realitas lokal yang lebih heterogen dan bermakna.

Dengan demikian kehadiran sejarah lokal tidak perlu ditakuti sebagai hal yang mengancam pendidikan multikultural. Bahwa pengungkapan sejarah lokal dikhawatirkan akan membuka luka atau justru memperuncing perbedaan tidak perlu terjadi apabila pengungkapan sejarah lokal tersebut sebagai upaya pengungkapan kejujuran dan sebagai media belajar dari masa lalu. Hal ini justru akan membantu perekatan persatuan melalui kupasan yang jujur dan demokratis. Sebab suatu luka yang ditutup-tutupi justru akan berakibat lebih fatal. Sebagai contoh bagaimana Orde Baru menutupi masalah dengan GAM, Gerakan Timor Leste dan sebagainya.

\section{Pengajaran Sejarah Lokal dalam Pendidikan Multikultural}

Dari kajian pendidikan multikultural dan sejarah lokal di atas, dapat dikompilasikan bagaimana strategisnya peran sejarah lokal dalam pendidikan sejarah dan pendidikan multikultural. Perbedaan-perbedaan pengalaman kelompok masyarakat tidak perlu ditakuti dan ditutup-tutupi. Dengan kesadaran sejarah, maka masyarakat akan lebih memahami dan arif menyikapi perbedaan masa lalu dan masa kini. Bagaimana mengembangkan pengajaran sejarah lokal dalam pendidikan multikultural? Strategi apa saja yang dapat dilakukan? Siapa saja yang terlibat?

\section{Belajar dari kesalahan masa lalu}

Salah satu ciri ilmu sejarah, adalah sifatnya yang diakronis (memanjang), berbeda dengan ilmu-ilmu sosial lainnya yang cenderung sinkronis (meruang). Selain itu fakta sejarah mempunyai sifat einmalig (sekali terjadi). Sifat diakronis dan einmalig ini mempunyai konsekuensi bahwa sejarah mempunyai berbagai dimensi dalam mengungkapkan berbagai fakta. Sifat keunikan sejarah juga memberikan ruang untuk lebih intensif mengembangkan penulisan dan pengajaran sejarah lokal. Penulisan tentang berbagai fenomena lokal, jelas akan memperkaya khazanah heterogenitas bangsa, sekaligus sebagai pijakan pendidikan multikultural yang efektif.
Salah satu permasalahan yang muncul adalah bahwa sebagian masyarakat lokal mempunyai jalan sejarah yang dianggap negatif, atau mungkin persinggungan konflik dengan komunitas lain. Contoh sederhana adalah konflik yang terjadi ratusan tahun lalu antara Suku Jawa dan Suku Sunda karena adanya Perang Bubad. Strategi Gadjah Mada menghancurkan Pajajaran di Majapahit membuat sakit hati dalam waktu yang lama masyarakat Sunda masa tersebut. Demikian halnya kasus pada masa kolonialisme Belanda. Kekalahan Perang Padri salah satunya disebabkan banyaknya pasukan sewaan Belanda dari Jawa. Begitu seterusnya sampai pada masalah-masalah kontemporer seperti konflik etnis Madura dan Dayak, konflik antarpemeluk agama dan sebagainya merupakan luka masa lalu yang dikhawatirkan akan membuka luka lebih lebar. Benarkah demikian? Bagaimana sejarah lokal menyikapi fenomena tersebut?

Sejarah lokal mempunyai kerangka kebijaksanaan menyikapi masa lampau. Biarlah masing-masing tempat mempunyai dan menguraikan sejarah yang berbeda dengan lokalitas lainnya. Justru dengan begitu akan muncul kesadaran 'ibaratnya saling mencurahkan hati', bahwa tiap lokalitas mempunyai masalah yang berbeda, sehingga bersamasama saling mencari jalan baru yang lebih terang.

Setiap bagian wilayah Indonesia, mempunyai banyak perbedaan sejarah dan kebudayaan. Sangat naif apabila dibuat penyeragaman sejarah dan budaya tersebut melalui kuriukulum nasional. Hendaknya perbedaan yang terjadi, maupun pertentangan yang pernah dialami antara sebagian daerah tidak perlu ditonjolkan tetapi juga jangan ditutup-tutupi, dengan lebih mengedepankan deferensiasi yang sifatnya menuju akomodasi.

Pengungkapan berbagai sisi kehidupan atau sejarah dalam lokalitas, akan semakin menggugah kesadaran betapa masing-masing budaya memiliki keanekaragaman nilai-nilai yang luhur. Tidak mungkin memandang bahwa sebagian masyarakat Papua yang masih menggunakan koteka dan sulit menggunakan pakaian modern sebagai masyarakat terbelakang dan tidak punya peradaban. Dengan berkaca pada sejarah, stereotype tersebut akan runtuh dengan kesadaran bagaimana proses manusia menemukan peradaban melalui waktu panjang. 
Selama ini pembelajaran sejarah telah memasukkan sejarah lokal dalam topik-topik kajian di kelas mulai pendidikan dasar sampai menengah. Sebagai contoh pembelajaran sejarah di SMA pasti mengajarkan berbagai perlawanan di berbagai daerah, perkembangan kerajaan-kerajaan Hindu Budna dan Islam di berbagai daerah di Indonesia merupakan contoh kajian sejarah lokal di dalam pembelajaran Sejarah di SMA.

\section{Menyajikan kasus-kasus lokal}

Idealnya pembelajaran sejarah selalu berangkat dari masalah dan fenomena-fenomena lokal, agar siswa mempunyai perasaan memiliki dan membutuhkan pelajaran yang mereka terima. Terutama pada masa orde baru, pengajaran sejarah terlihat begitu dipaksakan uniformitasnya. Bagaimana mungkin mengajarkan tentang kepahlawanan Pangeran Diponegoro dan Patih Gadjah Mada sama porsinya yang diajarkan di Jakarta dengan Papua. Tidak asingkah anak-anak Papua dengan tokoh Diponegoro dan Gadjah Mada? Tentu konsep pembelajaran sejarah yang ideal adalah pembelajaran yang mampu menyajikan kesejarahan yang dekat pada lingkungan anak didik. Kepahlawanan lokal akan lebih menarik dan menyenangkan disajikan kepada para siswa di daerah.

Pengajaran sejarah lokal mempunyai peran besar dalam upaya menghadirkan peristiwa kesejarahan yang dekat pada siswa. Elastisitas sejarah lokal mampu menghadirkan berbagai fenomena, baik berkaitan mulai dari latar belakang keluarga (family history), sejarah sosial dalam lingkup lokal, peranan pahlawan lokal dalam perjuangan lokal maupun nasional, kebudayaan lokal, asal-usul suatu etnis, dan berbagai peristiwa yang terjadi pada tingkat lokal. Siswa akan diajak memahami realitas sejarah mulai dari yang terkecil, hingga dalam bingkai nasional, dan global. Bagaimana menyajikan pengajaran sejarah lokal dalam mendukung pendidikan multikultural?

\section{Mengkomunikasikan berbagai perbedaan}

Setiap masyarakat mempunyai sisi 'baik' dan 'tidak baik' menurut penilaian yang sifatnya relatif. Atau ada yang mengatakan 'sejarah hitam' dan sejarah 'putih', walaupun dalam akademis tidak ada istilah tersebut. Apakah tidak dikhawatirkan bahwa penyajian sejarah lokal akan mendorong disintegrasi bangsa? Tentu saja pertanyaan tersebut merupakan kekhawatiran yang bisa dimengerti. Sebab penanaman nilai kesejarahan dengan menonjolkan luka-luka masa lampau, akan menghidupkan semangat pertentangan. Tetapi, hendaknya penyajian pengajaran sejarah mampu menghadirkan nilai objektif, dengan penuh muatan edukatif. Pendidikan Multikultural mengembangkan kesederajatan, yang berarti menghapus luka masa lalu dengan menghadirkan kehidupan yang lebih egaliter.

Pengajaran Sejarah tidak perlu terlalu menutup-nutupi realitas sejarah yang telah terjadi, tetapi hendaknya penyajian pengajaran sejarah mampu dihadirkan dengan penuh muatan edukatif akan kesadaran membangun nilai-nilai luhur secara bersamaan. Seperti terjadinya konflik pada tahun 1960-an, aksiaksi PKI dan organisaasi onderbownya telah menimbulkan luka yang mendalam dalam tubuh masyarakat, terutama di Jawa, Sumatera dan Bali. Demikian juga dengan gerakan penumpasan PKI, telah menimbulkan korban ratusan ribu sebagai akumulasi konflik masa sebelumnya. Haruskah pengajaran sejarah selamanya menutupi kasus yang sungguh terjadi dalam bangsa kita? Hendaklah dengan penuh kebijaksanaan dan kesadaran sejarah, pembelajaran bisa menanamkan bahwa pengalaman sejarah sebagai guru yang paling baik. Kesalahan masa lalu menjadi pengalaman untuk membangun masa depan bersama yang lebih baik.

\section{Pengembangan strategi pembelajaran}

Berbagai strategi pembelajaran sejarah lokal di atas akan lebih efektif apabila pembelajaran disajikan secara bervariatif. Sesuai dengan karakteristik pembelajaran sejarah yang diuraikan di depan, maka idealnya pembelajaran sejarah lokal disajikan dengan strategi yang menantang peserta didik. Pembelajaran sejarah seharusnya menekankan kegiatan belajar konstruktivistik yang terbuka terhadap perbedaan para siswa. Hal ini sangat penting untuk membantu siswa memahami diri dan masa lalu dirinya sebagai bagian lokal, nasional, dan global seperti diungkapkan Banks (2002, p.68).

"The knowledge construction component of multicultural education helps student understand how knowledge is construct- 
ed and how it is influential by the biases, experiences, and perceptions of historians and other researcher. It also helps students to construct own version of the past, present, and future."

Dalam pengembangan strategi pembelajaran, guru dituntut mampu merencanakan, menyajikan bahan ajar, mengembangkan metode, dan menggunakan penilaian yang mampu mendorong siswa untuk belajar akan berbagai perbedaan setiap kelompok masyarakat. Tugas-tugas yang bersifat kelompok dan individu untuk mempelajari masa lalu setiap kelompok masyarakat merupakan salah satu contoh efektif dalam mengembangkan strategi pembelajaran sejarah lokal.

\section{Pengembangan Kurikulum}

Pemberlakuan kurikulum 2006 atau lebih dikenal dengan sebutan "Kurikulum Tingkat Satuan Pendidikan (KTSP) merupakan tantangan tersendiri bagi praktisi dan pengambil kebijakan pendidikan sejarah. KTSP merupakan suatu konsep kurikulum yang menekankan pada pengembangan kemampuan melakukan kompetensi atau tugas-tugas dengan standar perfomasi tertentu, sehingga hasilnya dapat dirasakan oleh peserta didik, berupa penguasaan terhadap seperangkat kompetensi tertentu (E Mulyasa, 2004, p.39).

Salah satu aspek yang sangat menguntungkan dari KTSP adalah mengutamakan pendekatan pembelajaran yang bersifat kontekstual (alamiah), berangkat, berfokus, dan bermuara pada hakekat peserta didik untuk mengembangkan kompetensinya. KTSP juga memberikan kesempatan kepada daerah dan sekolah untuk mengembangkan kurikulum pendidikan. Hal ini berbeda dengan beberapa kurikulum sebelumnya yang lebih bersifat sentralistis. Kesempatan ini bisa digunakan untuk mengembangkan realitas lokal yang lebih menyentuh anak didik yang erat berkaitan dengan mata pelajaran yang dipelajari.

Sesuai konsep KTSP, sebebarnya pembelajaran sejarah lokal memiliki banyak tempat untuk dikembangkan. Seperti ditegaskan Conny Semiawan, bahwa Indonesia mengalami kurikulum yang sentralistis sangat lama. Kurikulum terpisat ini sangat bertolak belakang dengan pendidikan multikultural yang sangat menekankan kesamaan (2004, pp.4142). Dalam pembelajaran sejarah banyak di- jumpai anak-anak di daerah luar Jawa mengenal Pangeran Diponegoro sebagai pahlawan, tetapi tidak mengenal pahlawan yang ada di sekitar mereka. Hal ini disebabkan terpusatnya sumber belajar yang digunakan di seluruh Indonesia.

\section{Pengintegrasian dalam materi pembelajaran}

Waktu yang terbatas dalam pengajaran sejarah, tidak memungkinkan pengajaran sejarah lokal disajikan dalam bagian tersendiri. Pengajaran topik sejarah lokal dalam pendidikan dasar dan menengah dapat dilakukan dalam beberapa cara. Pertama, melalui penyisipan pada beberapa topik sejarah nasional yang mempunyai korelasi dengan peristiwa lokal. Misalnya dalam peristiwa revolusi kemerdekaan, guru di Sumatera dapat menonjolkan peranan Pemerintahan Darurat Republik Indonesia (PDRI). Kedua, melalui studi khusus terhadap perpustakaan, museum, maupun berbagai peninggalan sejarah. Hal ini dapat dilakukan satu semester sekali untuk mengenalkan sejarah dan budaya masyarakat setempat. Ketiga, melalui team teaching guru IPS bisa melakukan kolaborasi untuk membahas masalah lokal secara interdisiplin. Pengajaran sejarah lokal di sekolah juga perlu menghadirkan realitas fenomena pada lokalitas yang lain. Hal ini sangat penting dalam upaya mengerti dan berempati dengan keberagaman budaya lain.

\section{SIMPULAN}

Pendidikan multikultural sebagai salah satu alternatif untuk mewujudkan kehidupan berbangsa dalam bingkai multikultural. Upaya penanaman kesadaran multikultural salah satunya dilakukan melalui pendidikan Sejarah Nasional Indonesia. Namun, pengajaran Sejarah Nasional Indonesia selama ini terlalu sentralistis, cenderung politis ekspositoris, baik dalam kurikulum maupun pengembangannya. Akibatnya, siswa cenderung memahami sejarah bangsa Indonesia sebagai suatu keseragaman sejarah. Padahal setiap lokalitas mempunyai keunikan perbedaan masa lalu yang perlu dihadirkan dalam pembelajaran sejarah.

Salah saatu alternatif pengembangan sejarah dalam mendukung pendidikan multikultural adalah melalui pengajaran sejaarah lokal. Sejarah lokal adalah suatu unit kajian sejarah yang mengangkat topik/tema sejarah 
suatu tempat/lokalitas. Melalui studi sejarah lokal dapat menghadirkan realitas sejarah masyarakat peserta didik dan masyarakat luar lokalitas yang bisa menumbuhkan kesadaran dan sikap keberagaman. Implementasi KTSP semakin memberikan ruang kepada guru dan daerah untuk memasukan kajian sejarah lokal dalam mewujudkan perasaan dan kesadaran multikultural.

Konsep pengajaran sejarah lokal melalui KTSP dapat dilakukan melalui studi di luar kelas (out class of history teaching). Selain itu dapat pula dilakukan melalui pengajaran team teaching antara guru-guru IPS, dan menyisipkan materi sejarah lokal dalam membahas topik nasional yang berhubungan dengan permasalahan lokal. Melalui konsep ini, pengajaran sejarah akan lebih bermakna bagi siswa dan mendukung target pembelajaran.

\section{DAFTAR PUSTAKA}

Banks, A Jamer. (2002). An Introduction to Multicultural Education, 3rd-ed. Boston: A Pearson Education Company.

Conny Semiawan. (2004). "The Chalenge of a Multicultural Education in 1 Pluralistic Society: The Indonesian Case" dalam Jurnal Antropologi, Jakarta: FISIP UI.

E Mulyasa (2004). Kurikulum Berbasis Kompetensi, Bandung: Rosda Karya

Garvey, Brian \& Krug Mary. (1977). Models of History Teaching in the Secondary School, London: Oxford University Press

H.A.R. Tilaar. (2004). Multikulturalisme Tantangan-tantangan Global Masa Depan dalam Transformasi Pendidikan Nasional, Jakarta: Grassiondo

Kuntowijoyo. (1993). Metodologi Sejarah, Yogyakarta: Tiara Wacana (1995). Pengantar Ilmu Sejarah, Yogyakarta: Bentang

Lichtman, Alan J \& Valerie French. (1978). Historians and The Living Past, The Theory and Practice of Historical Stu$d y$, Arlington Heights: Harlan Davidson.
Nieto Sonia, "Affirming Diversity: The Sociopolitical Context of Multicultural Education" dalam Noel, Janna. (2000). Notable Selection in Multicultural Education, Guilford:Dushkin/McGraw-Hill.

Sartono Kartodirdjo (1992), Pendekatan Ilmu Sosial Dalam Metodologi Sejarah, Jakarta: Gramedia Pustaka Utama

Taufik Abdullah, "Dari Sejarah Lokal ke Kesadaran Nasional: Beberapa Problematik Metodologis" dalam Sartono Kartodirdjo (1985), Dari Babat dan Hikayat Dalam Sejarah Kritis, Yogyakarta: UGM Press.

(1992), Sejarah Lokal di Indonesia, Yogyakarta: Gadjah Mada University press

Jurnal, Paper, internet, dan koran

Anhar Gonggong. "Peranan Sejarah Lokal Untuk Mewujudkan Multikultural dan Demokrasi di Indonesia," Makalah Seminar Nasional XI Ikatan Himpunan Mahasiswa Sejarah Indonesia, Bali 2226 Februari 2005

I Gde Widja. "Multikulturalisme dan Peran Studi Sejarah Lokal”, Makalah Seminar Nasional XI Ikatan Himpunan Mahasiswa Sejarah Indonesia, Bali 22-26 Februari 2005

Hartono Kasmadi. "Multikultural Pendidikan", Makalah Seminar Nasional XI Ikatan Himpunan Mahasiswa Sejarah Indonesia, Bali 22-26 Februari 2005

Tim, "Pembangkangan Sipil dan Konflik Vertikal II" Kumpulan Makalah, Jakarta: Departemen Pendidikan Nasional

Musa Asy'arie. Pendidikan Multikultural dan Konflik Bangsa. Kompas, 03 September 2004

Parsudi Suparlan. Menuju Masyarakat Indonesia yang Multikultural, Jurnal Antropologi Indonesia, Simposium Internasional Bali ke-3 16-21 Juli 2002, www.scripps.ohiou.edu/news/cmdd/arti kel_ps.htm

Undang-Undang RI No 20 th. 2003 tentang Sistem Pendidikan Nasional 